AGRICULTURE AND BIOLOGY JOURNAL OF NORTH AMERICA

ISSN Print: 2151-7517, ISSN Online: 2151-7525, doi:10.5251/abjna.2011.2.4.610.615

(C) 2011, ScienceHu $\beta$, http://www.scihub.org/ABJNA

\title{
Genotype X seed production environment interaction on the performance of sorghum (Sorghum bicolor [L.] Moench) under irrigation
}

\author{
Faisal Elgasim Ahmed and Aisha O. A. Hussein
}

Faculty of Agriculture, University of Khartoum, 13314 Shambat, Sudan

Cell phone: +249912988847

\begin{abstract}
The ecological conditions prevailing during seed development, maturation and harvesting affect the physical and the physiological characters of the seed produced. The interactive of seed source and genotype on the performance of sorghum (Sorghum bicolor \{L.\} Moench) grown under irrigation was investigated. One-field experiment was conducted for two consecutive seasons (2006/07-2007/08) in the Demonstration Farm of the Faculty of Agriculture at Shambat. The seeds were obtained from four different locations, viz; two rain-fed locations (Damazin and Gedarif) and two irrigated locations (Khashm el Girba and Sinnar). The cultivars used were two improved (Tabat and Wad Ahmed) and two local cultivars (Arfaa Gadamak and Zahrat elgadambalia). The results indicated that, among the measured attributes, seed source had only significant effects on grain yield, number of heads per plant and number of seeds per head. The highest grain yield was obtained from seeds produced under rain-fed locations (2.0 tones/ha) compared to irrigated locations (1.6 tones/ha). The high yield of the rain-fed location was associated with greater number of heads per plant and number of seeds per head. Irrespective of the seed source, the improved cultivars out yielded the local ones in most of the parameters measured. In this respect, the improved cultivars had significantly greater number of grains/head and greater yield compared to the local cultivars. In contrast, the local cultivars were earlier compared to the improved ones. It is apparent, however, that sorghum seeds obtained from diverse environments can be grown provided that suitable cultivars are selected according to the prevailing environmental conditions.
\end{abstract}

Keywords: Sorghum; seed source; rain-fed; irrigation

\section{INTRODUCTAION}

Sorghum (Sorghum bicolor $\{$ L.\} Moench) is unique because it can consistently produce high yield even in certain semi-arid and arid areas where rice, wheat and corn are not well adapted (Ezeaku et al., 1997). The crop productivity is, however, constrained by the use of low yielding varieties and poor crop management (Hassan and ELasha 2008). Moreover, it has long been acknowledged that the environmental conditions during seed maturation may directly affect the seed because of the latter position on the plant, or indirectly by influencing the mother plant itself (Dhillon et al., 1978). The prevalence of environmental causes of variation over the genetic effects does not suggest that the importance of genotype on crop performance should be minimized.

In Sudan, sorghum is mainly cultivated under rain-fed where seed production occurs under suboptimal conditions as reported by many researchers (Farah, 1983; Ibrahim et al., 1998). While seed quality could be enhanced through genetic manipulation, more immediate improvement could be obtained through better exploitation of the environment in which the seed plant is grown. Although, sorghum has better drought tolerance than most other field crops, significant variation exists within species (Walulu et al., 1994; Tuinstra et al., 1996; Crasta et al., 1999). However, the interactive effect of genetic variation and seed source on differential seed quality is not known. Thus sorghum improvement efforts particularly in the development of cultivars and hybrids with high grain yield under diverse environmental conditions are needed. The objective of this study, therefore, is to investigate the effect of the interaction between genotype and production environment on the performance of improved and farmer's cultivars of sorghum under irrigation.

\section{MATERIALS AND METHODS}

A field experiment was conducted for two consecutive seasons (2006/07 and 2007/08) in the Demonstration Farm of the Faculty of Agriculture at Shambat (Latitude $15^{\circ} 40 \mathrm{~N}$, Longitude $32^{\circ} 32 \mathrm{E}$ and 
Altitude 230 meters asl). The soil of the experimental site is clayey (fine montomorilanitic, isohyperthermic entichromustert) with alkaline $\mathrm{pH}$. The climate of the locality is semi-arid with mean annual rainfall of about 100 to $200 \mathrm{~mm}$ and with maximum temperature about $42^{\circ} \mathrm{C}$ in summer and around $21^{\circ} \mathrm{C}$ in winter.

Treatments and layout: The experiment was designed to study the effect of seed source (production sites) on the performance of four sorghum (Sorghum bicolor \{L.\} Moench) cultivars grown under irrigation. The cultivars used were two improved cultivars (Tabat and Wad Ahmed) and two local cultivars (Arfaa Gadamak and Zahrat elgadambalia). The seed production sites chosen were two irrigated sites (Sinnar and Khashm ElQuirba) and two rain-fed sites (Damazin and Gedarif). The experimental treatments were arranged in a randomized complete block design with four replications in both seasons.

The land was prepared by disc ploughing, leveling and ridging $70 \mathrm{~cm}$ apart. The individual plot size was $4 \times 5$ meters consisting of five ridges of 4 meters in length. In each plot, the three inner ridges were used for sampling and the outer ridges were left as guard ridges. The seeds were treated before sowing by fungicide Thiram with a mixing ratio of $1: 3 \mathrm{~g}$ fungicide per $\mathrm{kg}$ of seeds. The insecticide Furidan (Carbofuran) was also used in split application: one dose at sowing and the other one 30 days after sowing. A basal dose of urea (100 kg N/ha) was added to the soil one month after sowing in both seasons.

The seeds were sown on the second week of July in both seasons and at a rate of 3-5 seeds per hole 15 $\mathrm{cm}$ a part on the top of the ridges. After sowing, the seeds were immediately irrigated and then irrigation was carried out at approximately 15 day intervals in both seasons. The plants were thinned to 2 plants per hole two weeks after planting. Three manual weeding were carried out in each season.

Characters studied: In each plot, plants from an area of $0.7 \mathrm{~m}^{2}$ were harvested to determine the following attributes: grain yield (ton/ha), dry matter production (ton/ha), number of heads/plant, grain weight $(\mathrm{g}) / \mathrm{head}$, number of grains/head and 1000seed weight $(\mathrm{g})$. The number of days to $50 \%$ flowering and to $95 \%$ physiological maturity was also recorded.

The data were subjected to analysis of variance using GENOSTAT-C. The Least Significant Difference test (LSD) was used to separate the differences between the means of the different characters according to Gomez and Gomez (1984).

\section{RESULTS}

Grain yield and dry matter production: The effects of seed source, cultivars and their interactions on grain yield and dry matter production were presented in table (1). Analysis of data indicated that there were significant differences due to treatments on mean grain yield in both seasons. In this regard, plants produced from seeds obtained from rain-fed locations significantly out yielded those obtained from irrigated locations (Table 1 ). The improved cultivars produced greater seed yield compared to the local cultivars in the two seasons (Table 1). The effect of treatments on mean dry matter production followed similar pattern as described for grain yield (Table 1).

Yield components: Although the differences due to the effect of treatments on mean number of heads/plant and weight of seeds per head were insignificant, seeds obtained from rain-fed locations produced plants with more number of heads and seeds weight per head than seeds obtained from irrigated locations (Table 2). Also, the improved cultivars significantly produced greater number of heads per plant and seeds weight per head compared to the local cultivars in both seasons (Table 2).

The effect of seed source and cultivars on mean number of seeds/head and 1000-seed weight is similar to its effect on the aforementioned characters. In this respect, seeds obtained from rain-fed locations resulted in plants with significantly greater number of grains per head compared to the other seed source (Table 3). The improved cultivars (Wad Ahmed and Tabat) produced significantly greater number of grains per head and lighter seeds compared to the local cultivars in both seasons (Table 3 ).

\section{Phonological attributes}

Statistical analysis of data revealed that only cultivars had significant effect on mean number of days to $50 \%$ flowering in both seasons (Table 4). In this regard, the local cultivars took fewer days to reach $50 \%$ flowering compared to the improved cultivars. The effects of seed source and cultivars on mean number of days to maturity was similar to its effect on the aforementioned character (Table 4). 
Agric. Biol. J. N. Am., 2011, 2(4): 610-615

Table 1. Effect of production site and cultivar on grain yield and dry matter production during 2006/07 and 2007/08 seasons

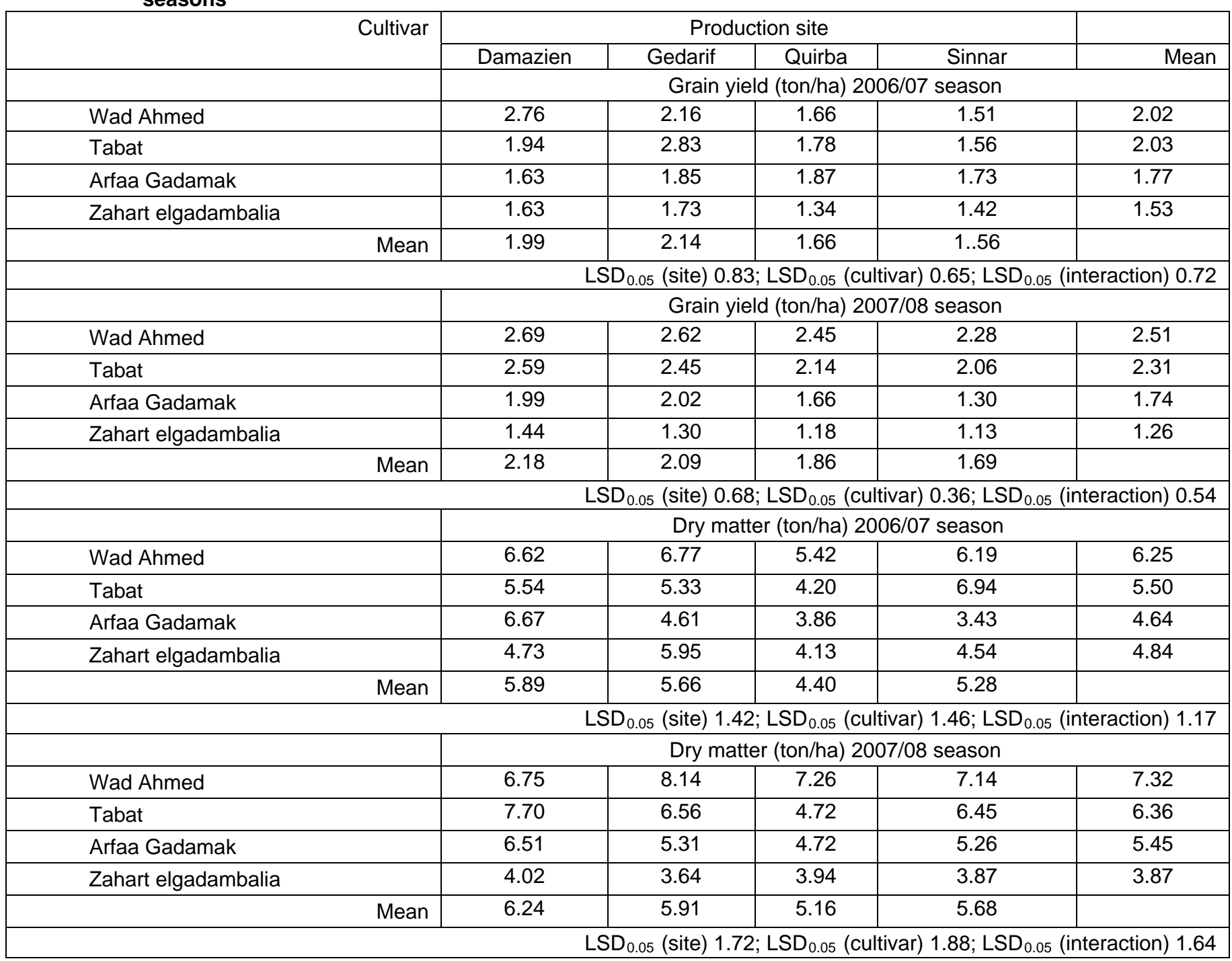

\section{DISCUSSION}

From the results obtained, it was clear that most of the parameters measured in this study were significantly affected by seed source. In this regard, seeds obtained from rain-fed locations showed better performance than those obtained from irrigated locations. This result may be attributed to the effect of ecological conditions prevailing during seed development, maturation and harvesting on the physical and the physiological characters of the seed produced as indicated by Dhillon et al. (1978). This further confirms the results reported by Ibrahim et al. (1998) who stated that seed production environment influences crop performance through its effect on the exploitation of the genetic potential of cultivars when grown under irrigation. Similar results were reported by Meseka et al. (2008) in maize.

In the present study, the highest grain yield and dry matter production were obtained from seeds produced under rain-fed conditions compared to irrigated locations. The greater plant dry weight under irrigation presumably may be due to the greater number of leaves and tillers produced by these plants. Supportive evidences were reported by Ibrahim et al. (1998). The average sorghum grain yields were 2.0 and 1.6 tones/ha for seeds produced under rain-fed and irrigation conditions, respectively. The high grain yield of the rain-fed location was associated with greater number of heads per plant and number of seeds per head. Previous research 
showed that there were significant and high positive correlation between grain yield and number of grains per head, head weight and 1000-grain mass (Kambal and Webster 1966; Aba and Obilana 1994; Aba and Zaria 2000; Ezeaku and Mohammed, 2006). However, partitioning of yield and yield components into direct and indirect effects revealed that the number of grains per head had the highest direct effect on grain yield while 1000-grain mass contributed indirectly to grain yield via head weight. This may explain the same association between grain yield and yield components observed in the present study.

The significant variations among the evaluated cultivars on most of the characters measured in this study may be attributed to the genetic factors as well as the environmental factors. Irrespective of the seed source, the improved cultivars (Wad Ahmed and Tabat) out yielded the local cultivars in grain production under irrigation conditions. The highest grain yield of the improved cultivars was associated with greater number of heads per plant and number of seeds per head. Similar results were reported by many researchers (Cheng et al., 1989; Ibrahim et al., 1998). Jeyaprakash et al. (1997) suggested that the higher yield of improved cultivars is related to their greater efficiency in dry matter production and to a higher harvest index (grain yield/total dry matter). Similarly, Ibrahim et al. (1998) showed that the greater dry matter production by the improved cultivars could be attributed to their better performance ability (taller and had greater number of nodes and leaves per plant) compared to the local ones under the prevailing environmental conditions.

Table 2. Effect of production site and cultivar on number of heads per plant and seed weight per head during 2006/07 and 2007/08 seasons

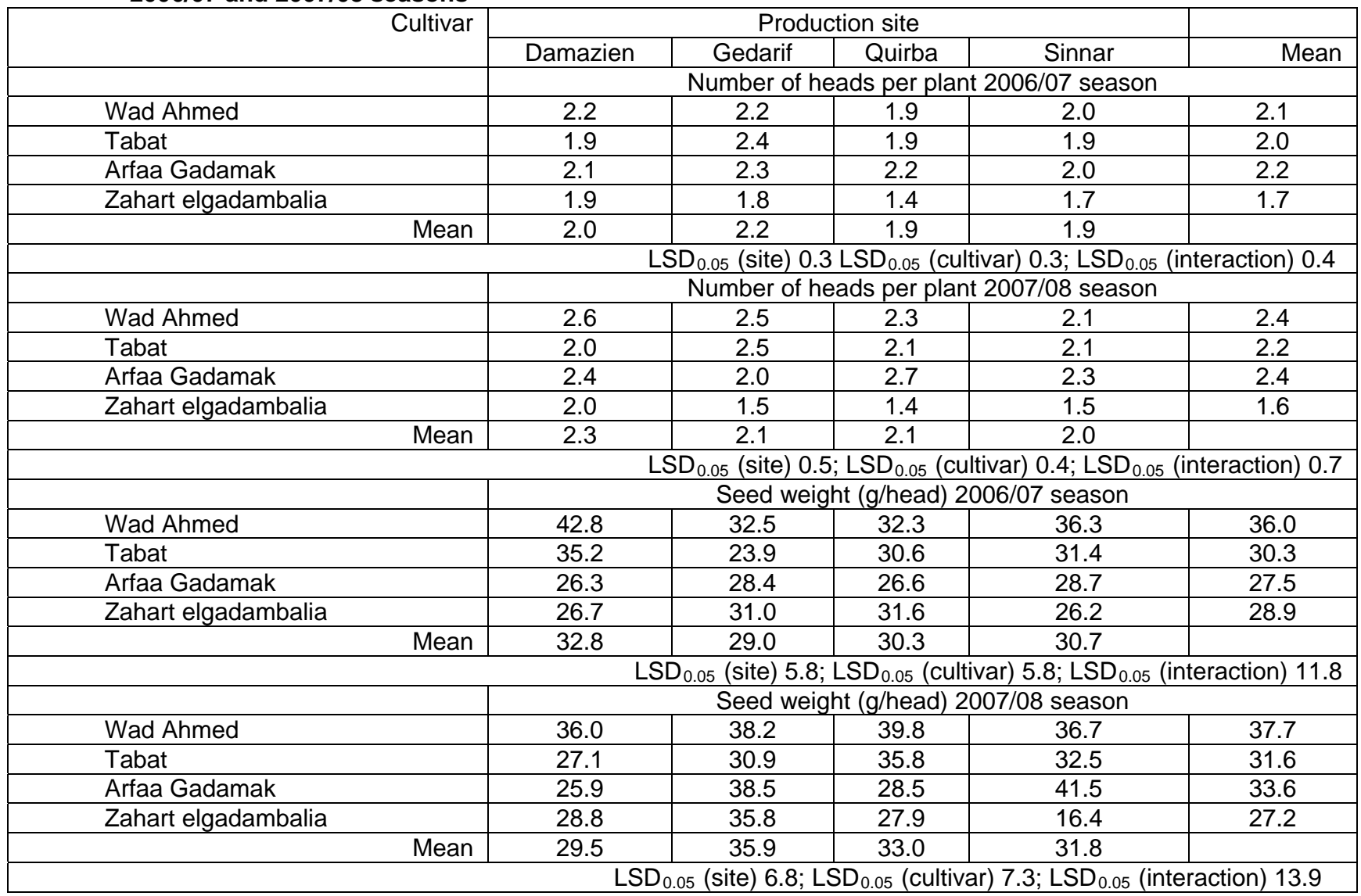


Agric. Biol. J. N. Am., 2011, 2(4): 610-615

Table 3. Effect of production site and cultivar on number of grains per head and 1000-seed weight during 2006/07 and $2007 / 08$ seasons

\begin{tabular}{|c|c|c|c|c|c|c|}
\hline & \multirow[t]{2}{*}{ Cultivar } & \multicolumn{4}{|c|}{ Production site } & \multirow[b]{2}{*}{ Mean } \\
\hline & & Damazien & Gedarif & Quirba & Sinnar & \\
\hline & & \multicolumn{5}{|c|}{ No. of grains/head 2006/07 season } \\
\hline Wad Ahmed & & 1440.0 & 1310.2 & 952.8 & 996.2 & 1174.8 \\
\hline Tabat & & 1395.5 & 1301.4 & 998.3 & 934.4 & 1157.4 \\
\hline Arfaa Gadamak & & 830.6 & 824.3 & 792.3 & 854.4 & 825.4 \\
\hline Zahart elgadambalia & & 765.8 & 897.3 & 844.8 & 861.8 & 842.4 \\
\hline & Mean & 1108.0 & 1083.3 & 897.1 & 911.7 & \\
\hline \multicolumn{7}{|c|}{$\mathrm{LSD}_{0.05}$ (site) 72.1; $\mathrm{LSD}_{0.05}$ (cultivar) 77.1; LSD $_{0.05}$ (interaction) 154.3} \\
\hline & & \multicolumn{5}{|c|}{ No. of grains/head $2007 / 08$ season } \\
\hline Wad Ahmed & & 1907.2 & 1890.3 & 1419.4 & 1393.8 & 1652.7 \\
\hline Tabat & & 2428.3 & 1102.3 & 1010.8 & 1029.0 & 1392.6 \\
\hline Arfaa Gadamak & & 962.8 & 1285.5 & 855.0 & 895.3 & 999.7 \\
\hline Zahart elgadambalia & & 1080.0 & 1175.5 & 875.3 & 754.0 & 971.2 \\
\hline & Mean & 1594.6 & 1363.4 & 1040.1 & 1018.0 & \\
\hline \multicolumn{7}{|c|}{ LSD $_{0.05}$ (site) 69.5; LSD 0.05 (cultivar) 86.7; LSD 0.05 (interaction) 155.2} \\
\hline & & \multicolumn{5}{|c|}{ 1000-seed weight $(\mathrm{g})$ 2006/07 season } \\
\hline Wad Ahmed & & 30.9 & 26.7 & 24.4 & 25.3 & 26.8 \\
\hline Tabat & & 29.2 & 27.6 & 28.1 & 27.2 & 28.0 \\
\hline Arfaa Gadamak & & 32.3 & 33.7 & 33.2 & 34.1 & 33.3 \\
\hline Zahart elgadambalia & & 35.4 & 33.8 & 36.1 & 35.1 & 35.1 \\
\hline & Mean & 32.0 & 30.5 & 30.5 & 30.4 & \\
\hline & & \multicolumn{5}{|c|}{ LSD $_{0.05}$ (site) 2.3; LSD 0.05 (cultivar) 2.6; LSD 0.05 (interaction) 4.6} \\
\hline & & \multicolumn{5}{|c|}{ 1000-seed weight $(\mathrm{g}) 2007 / 08$ season } \\
\hline Wad Ahmed & & 24.3 & 25.4 & 26.0 & 25.3 & 25.3 \\
\hline Tabat & & 29.6 & 22.1 & 34.7 & 23.9 & 27.6 \\
\hline Arfaa Gadamak & & 29.8 & 29.2 & 29.9 & 31.6 & 30.1 \\
\hline Zahart elgadambalia & & 28.9 & 32.1 & 29.3 & 25.0 & 28.8 \\
\hline & Mean & 28.2 & 27.2 & 30.0 & 26.5 & \\
\hline & & \multicolumn{5}{|c|}{$\mathrm{LSD}_{0.05}$ (site) 4.8; LSD 0.05 (cultivar) 3.9; LSD 0.05 (interaction) 8.3} \\
\hline
\end{tabular}

Table 4. Effect of production site and cultivar on phonological characters during 2006/07 and $2007 / 08$ seasons

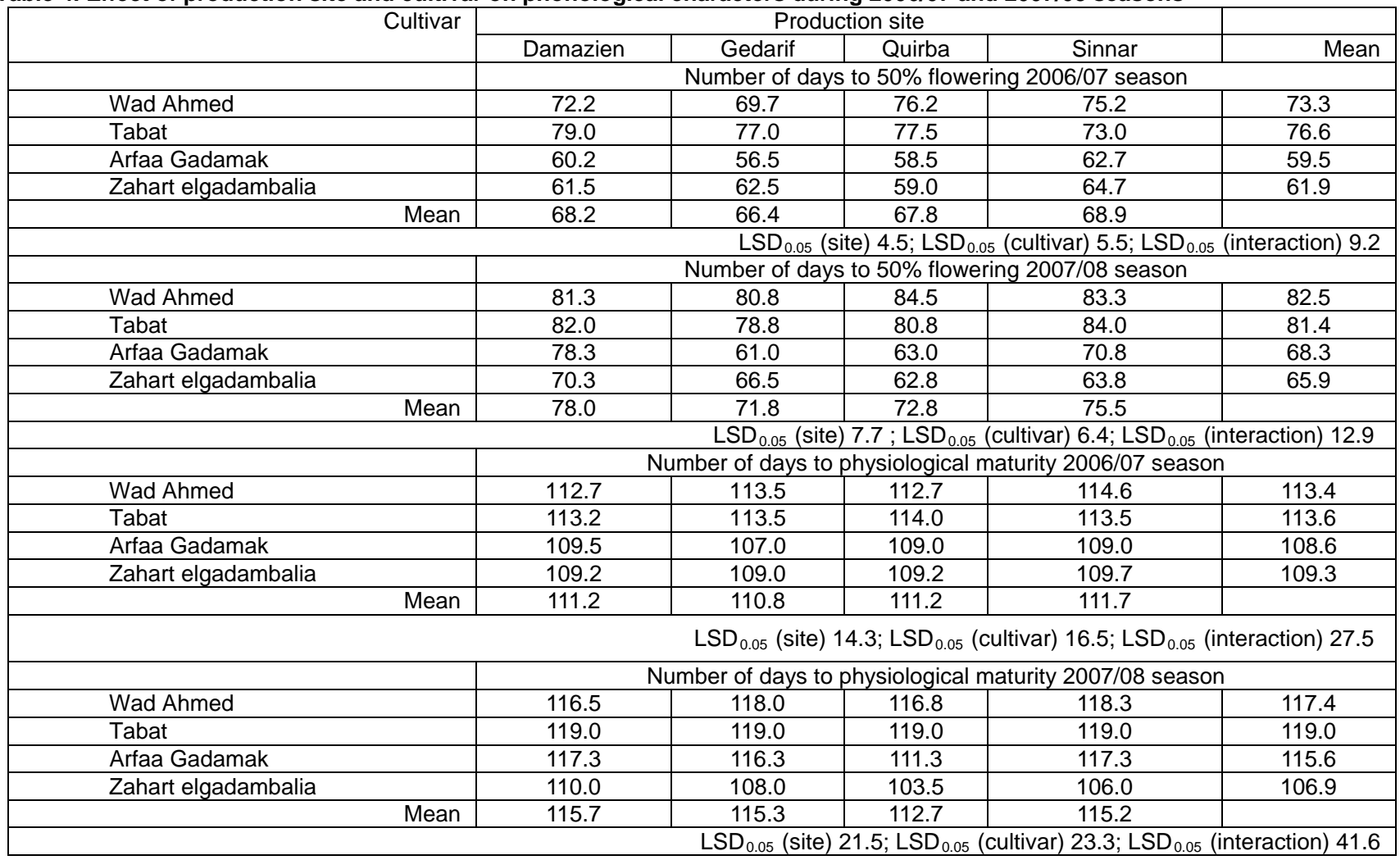


In contrast, the local cultivars were earlier and flowering occurred between 60 to 64 days compared to the improved cultivars which usually flower in about 74 to 81 days. Similar results were obtained by Ibrahim et al. (1998) who reported that the flowering time of the local types ranged from 56 to 64 days and Wad Ahmed flowered in about 70 days (medium cultivar). The earliness of the local cultivars was expected because these cultivars were mainly grown under rain-fed conditions. This is in accord with the results reported by Ibrahim et al. (1998).

\section{CONCLUTIONS}

The results indicated that seed source had significant effects on sorghum performance and the highest grain yield was obtained from seeds produced under rain-fed compared to irrigated locations. Also irrespective of the seed source, the improved cultivars out performed the local ones in most of the parameters measured in this study. It is apparent, however, that sorghum seeds obtained from diverse environments can be grown provided that suitable cultivars were selected according to the prevailing environmental conditions. Further work may be needed to establish the validity of seed source as an indicator of crop performance.

\section{REFERENCES}

Aba, D.A and Obilana, A.T (1994). Correlations in a mass selected population of sorghum. East African Agricultural Journal 60(1):45-50.

Aba, D.A and Zaria, A.A (2000). Correlation and path analysis for some characters contributing to grain yield in sorghum. Polymath. Journal 1(1):41-43.

Cheng, B.C, Liu, Q.Y and Jiang, H (1989). Analysis of grain weight of sorghum in diallel. Plant Breeding Abstract 60(3), 325.

Crasta, O.R, Xu, W.W, Rosenow, D.T, Mullet, J. and Nguyen, H.T (1999). Mapping of post-flowering drought resistance traits in grain sorghum: association between QTLs influencing premature senescence and maturity. Molecular and General Genetics 262: 579588.

Dhillon, G.S, Smith, P.E and Henderlong, P.R (1978). Effect of the ecological conditions and size of soybean seed used on the physical and physiological characters of the seeds produced. Indian Journal of Ecology 5: 229-232.

Ezeaku. I.E, Gupta, S.C and Prabhakar, V.R (1997). Classification of sorghum germplasm accessions using multivariate methods. African Crop Sci. Journal 7: 97108.

Ezeaku. I.E and Mohammed S.G (2006). Character association and path analysis in grain sorghum. African Journal of Biotechnology 5(14):1337-1340.

Farah, S.M (1983). Effects of supplementary irrigation on rain-grown sorghum [Sorghum bicolor (L.) Moench] in the Sudan. Journal of Agricultural Sci. 100(2):323-327.

Gomez, K.A and Gomez, A.A (1984). Statistical Procedure for Agricultural Research. John Willy and Sons, New York.

Hassan, A.E and Elasha, E.A (2008). Intercropping effect of using local cowpea on Striga hermonthica (Del.) control and grain yield of Sorghum bicolor (L.) Moench. Sudan Journal of Agricultural Res. 11:53-60.

Ibrahim, O.E, Elzein, I.N, Babiker, E.A and Suliman, I.A (1998). Performance of improved sorghum genotypes under irrigated and rain-fed situations of the Sudan. Sudan Journal of Agricultural Res. 1:1-7.

Jeyaprakash, P., Ganapathy, S. and Pillai, M.A (1997). Correlation and path analysis in sorghum (Sorghum bicolor L. Moench). Ann. Agric. Res. 18:309-312.

Kambal, A. E and Webster, O.G (1966). Manifestation of hybrid vigor in grain sorghum and the relations among the components of yield, weight per bushel and height. Crop Sc. 6:513-515.

Meseka, S.K, Menkir, A and Ibrahim, A.E.S (2008). Yield stability of maize inbred lines with differential reactions to drought evaluated under stress and non-stress environments. Gezira Journal of Agricultural Sci. 6(2):182-196.

Tuinstra, M.R, Grote, E.M, Goldsbrough, P.B and Ejeta, G (1996). Identification of quantitative trait loci associated with pre-flowering drought tolerance in sorghum. Crop Sci. 36:1337-1344.

Walulu, R.S, Rosenow, D.T, Wester, D.B. and Nguyen, H.T (1994). Inheritance of the stay green trait in sorghum. Crop Sci. 34:970-972. 